\title{
UMA ANÁLISE SOBRE O ENSINO DE HISTÓRIA E O LIVRO DIDÁTICO
}

Sonia Maria Gazola Pastro Diná Teresa Contiero*

Resumo: Este texto pretende expor algumas considerações acerca do Ensino de História e dos livros didáticos utilizados em sala de aula. Para isso, utilizamos a nossa própria experiência enquanto professoras de $1^{\circ}$. e $2^{\circ}$. graus.

Unitermos: ensino de história; livro didático; indústria cultural.

\section{I.}

A idẻia de Ensino na escola brasileira hoje supõe a reconstrução social cujos participantes assumam um compromisso histórico na elaboração das respostas às exigências da comunidade.

Diante do momento histórico em que vivemos é bastante sensivel e importante fazer-se uma reflexão, um questionamento, sobre o Ensino de História.

Como instituição sistemática e compromissada com a realidade social, a escola e o ensino, e no nosso caso específico, o ensino de História, tem como finalidade propiciar aos alunos condições para a formação de indivíduos críticos, participativos e capazes de atuar na transformação da sociedade.

Lamentavelmente, essa não tem sido a realidade. E talvez um dos instrumentos condicionadores deste status quo, entre outros tantos, tem

\footnotetext{
Professoras de História da Rede Pública Estadual de Ensino de $1^{\circ}$ e $2^{\circ}$. graus Nova Esperança - PR.
} 
PASTRO \& CONTIERO. Uma análise sobre o ensino de histónia.

sido os livros didáticos. Quase sempre, os livros didáticos mostram a história pelos olhos da classe dominante, ocultando o outro lado da História, ou seja, a história das classes subalternas, como se elas não tivessem tido nenhuma importância ou participação na formação dos processos históricos.

Neste sentido, podemos indagar sobre que tipo de história os estudantes brasileiros tem recebido. Trata-se de uma história a serviço das classes dominantes, factual, atenta às coisas do passado, ocupando uma função ideológica dentro da estratégia da ordem, que reflete os interesses das classes que detêm o poder. $\mathrm{O}$ que reforça esta idéia é o fato de se procurar oferecer aos estudantes uma história elaborada a partir de fatos fragmentados que impedem a compreensão de processos como um todo, visando escamotear a dominação da classe existente. Uma história que omite o conflito entre as classes, não dando importância ao papel que o indivíduo ocupa no processo de produção.

Embora o currículo em vigência tente propor o contrário, a realidade do ensino e a atuação dos professores em sala de aula no diaa-dia refletem o que dissemos acima. Devemos, no entanto, ressaltar a experiência de muitos professores, que em seu árduo e perseverante trabalho vem procurando contribuir com a transformação desejada.

Assim, entendemos que estudar ou analisar a história é procurar estabelecer um diálogo entre o presente e o passado (Chesneaux, 1977), tendo como referência a história vivenciada, acompanhada pelo conteúdo historiográfico e também pelas memórias deixadas pelos homens.

II.

Sabemos que o conhecimento histórico não é um dado pronto e acabado, mas uma constante reelaboração e construção que se dá a partir de necessidades e problemas colocados pelo cotidiano. A percepção de possibilidades de elaboração do conhecimento deve tomar o fio condutor de todo o trabalho do conhecimento histórico. 
PASTRO \& CONTIERO. Uma análise sobre o ensino de história.

A história é escrita a partir de fatos que se desenvolvem de uma problemática central Os fatos compõe a história, cabendo portanto, ao historiador recorrer às teorias e às fontes para melhor explicitá-las.

Ao analisarmos o Ensino de História ministrado nas escolas, faz-se mister compreendermos que estas são um reflexo da sociedade na qual estão inseridos.

Hoje, muitos se preocupam com a formação dos professores de história e também com a realidade do ensino em nossos dias. Esta preocupação se estende em muitas áreas diferentes nas universidades. Como nos afirma Déa Fenelon:

$O$ historiador se julga distanciado do social, concretizando assim a distorção entre o fazer $e$ o escrever. $O$ conhecimento é visto como algo passivo. despolitizado e sempre intelectualizado e a história se produz dentro desses limites institucionais com esta perspectiva não consegue mais do que formar profissionais que serão os reprodutores destas percepçōes (Fenelon, 1985).

A grande maioria de nossos estudantes não compreendem a história que estudam e muito menos a sua finalidade. Talvez seja este um dos motivos do desinteresse dos estudantes de $1^{\circ}$. e $2^{\circ}$. graus pelo ensino de história. $\mathrm{O}$ que aumenta em muito a responsabilidade do professor em apontar aos alunos novos caminhos que visem criar o interesse pelo conhecimento e compreensão da história como um processo, pois é de nosso conhecimento que há um certo comprometimento da História oficial com certos interesses da classe dominante.

Fica então a dupla tarefa: repensar nossos equívocos e rever a historiografia que analisa a História e o ensino de história. Só assim, poderemos contribuir com a transformação da sociedade em que vivemos.

O livro didático é o material que propõe a uma ação educativa, cujo conteudo é pensado e elaborado tendo em vista as concepções e os 
PASTRO \& CONTIERO Uma análise sobve o ensino de história.

valores que o produtor, no caso do autor, e a escola consideram desejáveis para sua clientela.

Assim sendo, o grande problema deste questionamento, não é o aspecto pedagógico e didático do livro escolar, mas sim o aspecto ideológico e dos valores explícitos ou implícitos, presentes nos conteúdos.

O livro didático é um dos responsáveis pelo conhecimento histórico que constitui o que poderia ser chamado de conhecimento do homem comum. É ele o construtor doconhecimento historico daqueles cujo saber não vai além do que lhes foi transmitido pela escola de primeiro e segundo graus (Abud, 1984).

Esse homem comum acredita na história factual, onde os personagens principais são os heróis. Portanto, a história de alguns homens são transformadas em História da humanidade, causando um grave problema, porque nem todo mundo se sente a altura de imitá-los, pondo-se temidamente à margem de qualquer processo de decisão.

Mais preocupante se toma o livro didático, à medida que, vem assumindo uma outro função: a de informar também o professor. Este, em razão das deficiências de formação e das condições de trabalho que enfrenta, não procura outro tipo de material para preparação de aulas, quer expositivas ou de qualquer outra natureza. Dessa maneira, o trabalho do professor tem se tranformado num reforço das idéias contidas no livro didático adotado, que é visto pelos alunos, como a única fonte dígna de confiança.

Mesmo no Paraná, a partir de 1990 , com a implantação do novo currículo básico, os usuais e velhos livros didáticos foram mantidos como recursos nas escolas. Com isso, tanto a concepção de história como a seleção do que deve ser ensinado também foram mantidas (voltamos a reforçar, mais uma vez, que estamos abordando a questão genericamente, não considerando aqui as experiências transformadoras, que ainda são poucas, mas com certeza, profícuas), passando a idéia de que existe uma história correta que deve persistir na formação do 
PASTRO \& CONTIERO. Uma andise sobre o ensino de história.

estudante. Falta então a incorporação das idéias transmitidas pelas novas propostas historiográficas, vistas também não como verdades imutáveis, mas como afirmação possiveis de revisão na medida em que se repensa e se reescreve constantemente a história.

Um exemplo, é o caso de Jim Sharpe, em seu artigo intitulado $A$ História vista de Baixo (Burke, 1992), onde ele trata questões que abordam as dificuldades dos historiadores que trabalham a história por um outro ângulo, e que ao buscar reconstruir a experiência das classes subaltemas, ainda assim, trabalha muito restritamente a variedade de fontes de pesquisas à sua disposição.

Segundo o autor,

Ocultou-se uma questão fundamental: $A$ História vista de baixo consitui uma abordagem da história ou um tipo distinto de história ? Como abordagem, a História vista de Baixo preenche comprovadamente duas funções imporlantes. A primeira é servir como corretivo à llistónia da elite, para mostrar. por exemplo, que a batalha de Waterloo envolveu tanto o soldado como o Duque. A segunda é que, oferecendo esta abordagem alternativa, a Histónia vista de Baixo abre a possibilidade de uma sintese mais rica da compreenssão histórica de uma fusão da história da experiencia do cotidiano das pessoas com a temática dos tipos mais tradicionais de Ihistónia(Sharpe, 1992).

$\mathrm{Na}$ verdade essas preocupações estão em boa parte entre os profissionais da produçãc histórica, mas o problema se complica quando se depara com a chamada história de vulgarização, ou da divulgação dos saberes, que é aquela contida e contada nos livros didáticos. 
PASTRO \& CONTIERO. Uma análise sobre o ensino de histónia.

Pelo exposto, concluímos que o Ensino de História atravessa por uma fase crítica devido a varios fatores tais como:

1) podemos perceber que os professores de História que ministram aulas no $1^{\circ}$ e $2^{\circ}$ graus, pela deficiência da formação e pela falta de recursos financeiros, acabam quase sempre recorrendo aos livros didáticos que transmitem uma história factual e fragmentada. Lamentavelmente, ao transmitirmos esta história para os alunos, estamos contribuindo para o desinteresse dos mesmos, pois assim, eles não conseguem correlacionar os conteúdos trabalhados com sua realidade. Se os professores de história não conseguem se apresentar agentes ou produtores do processo histórico, dificilmente conseguirão que os alunos o sejam.

2) os livros didáticos de história utilizados nas escolas estão dissociados da realidade do mundo. Jamais poderá ser um instrumento vivo se o mesmo não se utilizar de uma linguagem adequada que venha de encontro às reais necessidades dos nosso alunos. Um material que adote uma visão crítica da sociedade em que vivemos, que estabeleça questionamento de valores sociais, morais, religiosos, políticos e que caminhem à uma transformação da sociedade.

o professor deve usar o conteúdo de forma que propicie a problematização do presente e do passado trabalhando de forma comparativa à produção histórica de várias sociedades: produção material, poder imaginário, cotidiano, etc.. indicando a multilinearidade da História, relacionando a História dos individuos com coletivo dos grupos, classes sociais, entendendo a História como ação de todos os homens.

O livro didático não deve propiciar apenas a memorização com exercícios repetitivos. Mas sim levar o aluno à reflexão e à compreensão do assunto tratado, recorrendo às várias fontes de pesquisa entre as quais: fotografias, filmes, propaganda, música, teatro, etc. Como nos diz Angelo Priori:

\footnotetext{
Por pior que seja o livro didatico, por mais generalizante e por mais factual que se apresente, alunos e professores poderão elaborar um trabalho critico,
} 
PASTRO \& CONTIERO. Uma análise sobre o ensino de história.

que consiga, com a introdução de novas fontes, ampliar os limites da análise historica (Priori, 1995).

É uma pena que ainda hoje, no final do século $\mathrm{XX}$, privilegia-se a visão do colonizador, do branco, da classe dominante, através do conjunto dos elementos que compõem o ideário liberal. Neste ideário, a sociedade é vista de forma harmônica, onde a igualdade, liberdade e a propriedade são considerados direitos naturais, garantidos pela Lei e não por uma construção histórica

E por tudo isso, que os professores e profissionais de história tem o dever de repensar o ensino de história, procurando colocá-lo como um instrumento capaz de contribuir com a transformação da sociedade.

\section{Referências Bibliográficas}

ABUD, Kátia. "O livro didático e a popularizaçãso do saber histórico", In: SILVA, Marcos (Org). Repensando a história. $2^{\circ}$. ed. São Paulo: Marco Zero/ ANPUH, 1984.

CHESNEAUX, Jean. Hacemos tabla rasa del pasado? Madrid: Siglo XXI, 1977.

FENELON, Dea R. "A formação do profissional de história e a realidade do ensino". Cademo Cedes (8). São Paulo: Cortez, 1985 .

PRIORI, Angelo. “A concepção de história nos manurais didáticos: uma releitura". História e Ensino Londrina/ UEL,n 01, 1995.

SHARPE, Jim. "A história vista de baixo". In: BURKE, Peter. (Org). A Escrita da História. São Paulo: Edunesp, 1992. 